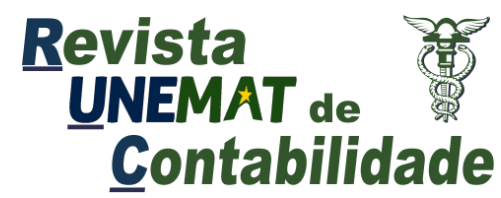

v. 10, n. 19,2021

\title{
EDUCAÇÃO FINANCEIRA: UM ESTUDO DO PERFIL DO COMPORTAMENTO FINANCEIRO DE ACADÊMICOS DOS CURSOS DE GESTÃO
}

\author{
Felipe Muhlhausen \\ Bacharel em Ciências Contábeis pelo Centro Universitário Estácio de Sá \\ E-mail: felipemuhlhausen@outlook.com \\ Igor Pereira da Luz \\ Doutorando em Ciências Contábeis pela Universidade Federal de Santa Catarina \\ E-mail: i.pereiradaluz@gmail.com \\ Ronan Reis Marçal \\ Doutorando em Ciências Contábeis pela Universidade Federal de Santa Catarina \\ E-mail:m.ronanreis@gmail.com
}

\section{RESUMO}

Este estudo teve como objetivo analisar a influência dos cursos de gestão no comportamento de controle financeiro dos estudantes de uma universidade particular do estado de Santa Catarina. Para tal, foi aplicado presencialmente um questionário com discentes regularmente matriculados em uma universidade particular do estado de Santa Catarina. A amostra final foi composta por 550 observações válidas e, diante da análise regressões múltiplas, foi possível inferir que os alunos pertencentes ao grupo de cursos de gestão (administração e ciências contábeis) tendem a ser mais educados financeiramente que os alunos dos demais cursos. As contribuições deste estudo confirmam a tendência de que o contato com conceitos acerca de finanças pessoais favorece a educação financeira do indivíduo, reforçando a necessidade da ampliação de estudos desse âmbito dada a já explicitada deficiência em termos de educação financeira do cidadão brasileiro médio, conforme reportado por pesquisas correlatas.

Palavras-chave: Educação Financeira; Comportamento Financeiro; Planejamento Financeiro; Cursos de Gestão.

\begin{abstract}
This study aimed to analyze if the students of management courses have a better financial education than the students of the other courses. To this end, a questionnaire was applied in person with students regularly enrolled in a private university in the state of Santa Catarina. The final sample consisted of 550 valid observations and, considering the multiple regression analysis, it was possible to infer that students belonging to the group of management courses (administration and accounting sciences) tend to be more financially educated than students from other courses. The contributions of this study confirm the tendency that contact with concepts about personal finance favors the individual's financial education, reinforcing the need to expand studies of this scope given the already explicit deficiency in terms of financial education of the average Brazilian citizen, as reported. by related research.
\end{abstract}




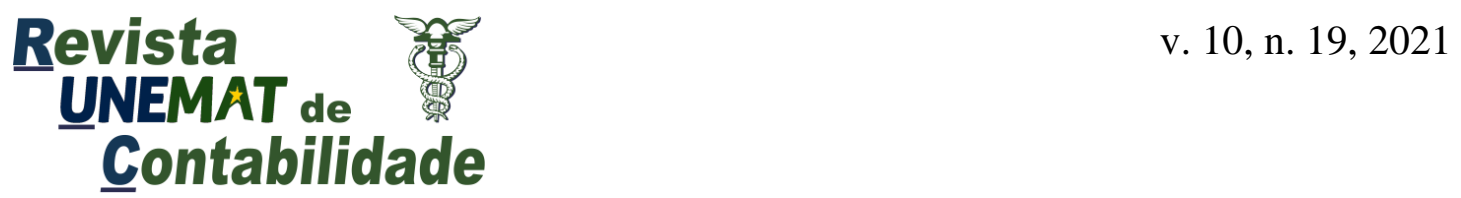

A presente pesquisa busca reforçar as vantagens proporcionadas pelo conhecimento acerca das finanças pessoais aos indivíduos, além de demonstrar a urgência da adoção de medidas de melhoria no sentido de orientação dos cidadãos sobre a educação financeira e o consumo consciente. Isso é corroborado por Halles, Sokolowski, e Hilgemberg (2008), ao explicar que a educação financeira é uma das ferramentas que promove o desenvolvimento econômico.

Tendo em vista o cenário apresentado, e levando em consideração o fato de que os cursos de Administração, Ciências Contábeis, e Ciências Econômicas estão ligados às finanças pessoais, surge a seguinte questão: Qual a diferença no comportamento de controle financeiro dos estudantes da área de gestão em comparação com estudantes das demais áreas?

Para responder o problema proposto, foi proposto como objetivo geral analisar a influência dos cursos de gestão no comportamento de controle financeiro dos estudantes de uma universidade particular do estado de Santa Catarina. O intuito foi verificar se os estudantes dos cursos da área de gestão conseguem gerir melhor seus recursos para atingir seus objetivos em função de possuírem mais contato no dia a dia com o campo das finanças. Para atingir esse objetivo, foi elaborado um questionário como instrumento de pesquisa que veio a ser aplicado de forma presencial aos discentes da referida instituição de ensino superior.

O trabalho se justifica em função das diversas notícias sobre o crescente endividamento do cidadão brasileiro e do intuito de demonstrar que um planejamento financeiro pessoal adequado colabora na obtenção de uma vida financeira mais estável, favorecendo o equilíbrio das finanças e evitando o endividamento pessoal. Dessa forma, confirmadas as expectativas da pesquisa, os resultados passam a contribuir para a sociedade, como um todo, de forma prática, uma vez que indivíduos menos propensos ao endividamento e mais conscientes acerca de seu perfil de consumo tendem a propiciar uma evolução no aspecto macroeconômico em sentido amplo.

\section{REFERENCIAL TEÓRICO}

\subsection{Educação Financeira}

No Brasil, até 1994, as pessoas eram compelidas a gastar, em curto prazo, toda a sua renda, uma vez que a inflação corroía o valor do dinheiro em pouco tempo (PASTORE; PINOTTI, 1999). A economia nacional só viria a ser estabilizada a partir da implantação do plano Real, que elevou a renda das famílias em termos reais (ROCHA, 2000). Após o processo de estabilização da 


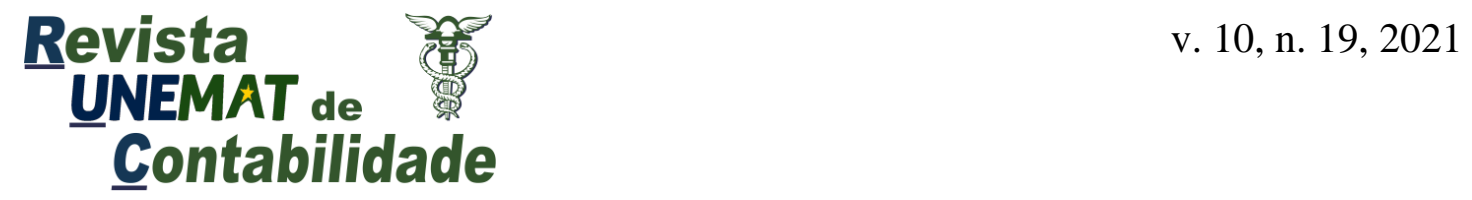

economia, o acesso ao crédito no Brasil foi facilitado para a população, o que possibilitou um aumento do poder de compra, mas devido à falta de prática do planejamento financeiro pessoal, os brasileiros, em média, se endividaram. É fato que o crescimento da oferta de crédito, sem o devido controle, gera inadimplência (SAVOIA; SAITO; SANTANA, 2007).

No contexto nacional, os principais fatores para a inadimplência do brasileiro são o desemprego (37\%), a redução de renda (24\%) e o descontrole financeiro (12\%) (CNDL; SPC BRASIL, 2018). No mais, seis a cada dez pessoas têm pouco conhecimento sobre sua própria renda, mesmo assim, 40\% ainda tomam atitudes sem pensar nas consequências (CNDL; SPC BRASIL, 2018). Para melhorar esse panorama, faz-se importante a discussão sobre a educação financeira.

Educação financeira é o meio pelo qual as pessoas melhoram sua compreensão sobre produtos financeiros e seus conceitos (OCDE, 2005). A educação financeira pode ser mensurada pelo grau de entendimento dos principais conceitos financeiros, com vista a ter confiança para administrá-los de forma apropriada nas decisões de curto e longo prazo, mesmo com mudanças nas condições econômicas (REMUND, 2010). Uma vez que sejam capacitadas e bem orientadas, as pessoas podem ter mais consciência das oportunidades e riscos que envolvem cada atitude tomada, assim contribuindo para a formação de sociedades responsáveis (OCDE, 2005).

O objetivo dessa vertente da educação é "permitir a melhora de nossa qualidade de vida, seja hoje ou no futuro, atingindo de forma inteligente nossos objetivos pessoais" (TOMMASI; LIMA, 2007, p.14). A educação financeira é, deste modo, uma ferramenta que está diretamente ligada à qualidade das decisões financeiras que as pessoas tomam, e que, consequentemente, impactam seus investimentos, seus níveis de endividamento e a possibilidade de inadimplência. Logo, para um bom desempenho financeiro faz-se necessário um planejamento financeiro pessoal.

"Planejamento financeiro pessoal significa estabelecer e seguir uma estratégia precisa, deliberada e dirigida para a acumulação de bens e valores que irão formar o patrimônio de uma pessoa e de sua família" (FRANKENBERG, 1999, p. 32). Estudos como o de Halles, Sokolowski e Hilgemberg (2008) apontam que um bom planejamento é essencial para controlar as finanças, auxiliando a ajustar a renda do cidadão conforme suas necessidades (GIARETA, 2011). Esse processo deve ser individual, visto que pessoas possuem estilos de vida e metas diferentes (ARCURI, 2018). No mais, o planejamento pode ser realizado com o uso de planilhas eletrônicas 


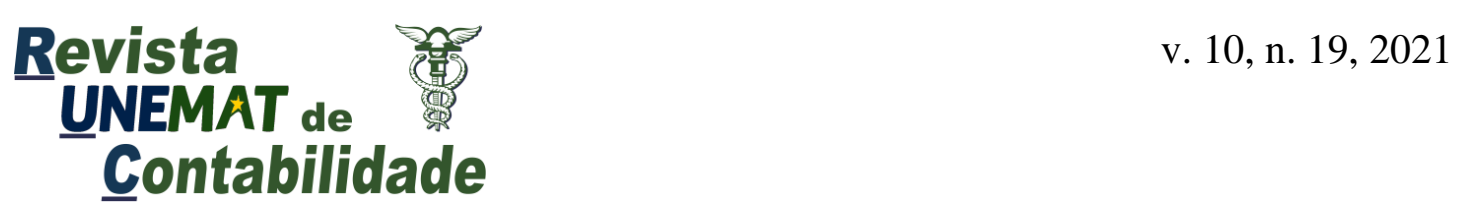

Essa pesquisa aponta, por exemplo, que as pessoas conhecem como investimento o carro particular para uso próprio, sendo essa crença representada por $41 \%$ dos entrevistados. Achados como este corroboram com o entendimento de que o brasileiro não conhece os produtos financeiros disponíveis, diagnosticando, portanto, uma possível razão para que a poupança, mesmo tendo a menor rentabilidade, ainda seja frequentemente procurada pelos brasileiros quando se trata de investimentos.

\subsection{A Educação Financeira no Ensino Superior}

Conforme preconizam Savoia, Saito e Santana (2007), não há obrigatoriedade da educação financeira no sistema de ensino. O Ministério da Educação (MEC) prioriza um processo de aprendizagem multidisciplinar, incentivando o raciocínio e a capacidade de aprender, visando a inserção dos estudantes na vida adulta. Diante dessa realidade, os brasileiros não adquirem o hábito de poupar, pois não foram educados na infância ou sequer na vida adulta a gerir o próprio dinheiro, já que o sistema de ensino comum não privilegia este tema (HALLES; SOKOLOWSKI; HILGEMBERG, 2008).

Alguns estudos abordam a questão da educação financeira no contexto universitário, sendo apresentados alguns deles, a seguir. Vieira et al. (2011) comparam o nível de conceitos sobre consumo, investimento e poupança entre os alunos das primeiras e últimas fases dos cursos de Administração, Ciências Econômicas e Ciências Contábeis de uma universidade pública do norte do Paraná mediante uma amostra de 610 estudantes. A hipótese de que os alunos dos cursos pesquisados no último ano possuíam mais competências para reconhecer e manipular os conceitos chave de finanças do que os alunos dos mesmos cursos nas séries iniciais, não foi confirmada.

Donadio (2014) analisou a educação financeira de estudantes universitários e suas relações com variáveis psicológicas e sociológicas. A pesquisa demonstrou que as disciplinas relacionadas às finanças tinham relevância no nível de educação financeira dos estudantes. A pesquisa demonstra, também, que os alunos que tinham uma preocupação maior com o bem-estar em curto prazo detinham menor nível de educação financeira.

Rodrigues e Carvalho (2017) realizaram um estudo com os estudantes da Universidade Federal do Piauí no qual foi analisado o nível de educação financeira dos acadêmicos de Administração e Contabilidade. Por meio do estudo realizado, os autores constataram que o nível 
a partir do estudo de Silva, Silva Neto e Araújo (2017). O Quadro 1 apresenta as assertivas do questionário.

Quadro 1 - Questionário de Pesquisa

\begin{tabular}{|c|c|}
\hline Bloco & Variáveis \\
\hline \multirow{6}{*}{$\begin{array}{l}\text { Caracterização dos } \\
\text { estudantes }\end{array}$} & Curso \\
\hline & Fase \\
\hline & Gênero \\
\hline & Idade \\
\hline & Número de dependentes \\
\hline & Moradia \\
\hline \multirow{2}{*}{ Receita } & Você trabalha atualmente? \\
\hline & Renda mensal pessoal \\
\hline \multirow{3}{*}{ Endividamento } & Você em algum momento teve seu nome negativado em algum sistema de crédito? \\
\hline & Você se considera endividado? \\
\hline & $\begin{array}{l}\text { Qual o percentual do seu rendimento mensal está comprometido com } \\
\text { prestações/obrigações mensais? }\end{array}$ \\
\hline \multirow{2}{*}{$\begin{array}{l}\text { Poupança e } \\
\text { Investimento }\end{array}$} & Quanto, em termos percentuais, você consegue poupar da sua renda mensal? \\
\hline & Você possui alguma de investimento? \\
\hline \multirow{3}{*}{ Orçamento e Controle } & Anoto e controlo gastos pessoais \\
\hline & Estabeleço metas financeiras \\
\hline & Sigo um orçamento ou plano de gastos \\
\hline
\end{tabular}

Fonte: Adaptado de Silva, Silva Neto e Araújo (2017).

Com o auxílio das respostas percebidas diante do referido instrumento de pesquisa foi possível desenvolver o modelo responsável pela verificação da hipótese geral de pesquisa, qual seja:

\section{H1: Discentes dos cursos de gestão são mais educados financeiramente que discentes}

\section{de áreas não relacionadas à gestão.}

Para a análise dos resultados foi feita, em primeira instância, uma verificação acerca da estatística descritiva dos blocos visando a educação financeira dos dois grupos estudados. Após a análise da estatística descritiva, foi realizada a análise fatorial para as respostas obtidas no questionário no subgrupo de orçamento e controle, já que tais respostas foram mensuradas em uma escala Likert de 5 pontos e, portanto, não apresentavam as propriedades métricas necessárias para a inclusão em um modelo de regressão linear.

Este procedimento, que buscou reduzir o número de itens em apenas uma unidade, foi feito sob a forma de Análise dos Componentes Principais (ACP) mediante o método de rotação Varimax, seguindo os critérios dispostos por Fávero et al. (2009) no que se refere às cargas fatoriais, às comunalidades $\left(\mathrm{H}^{2}\right)$, ao resultado de Kaiser-Meyer-Olkin (KMO), ao Teste de Esfericidade de 


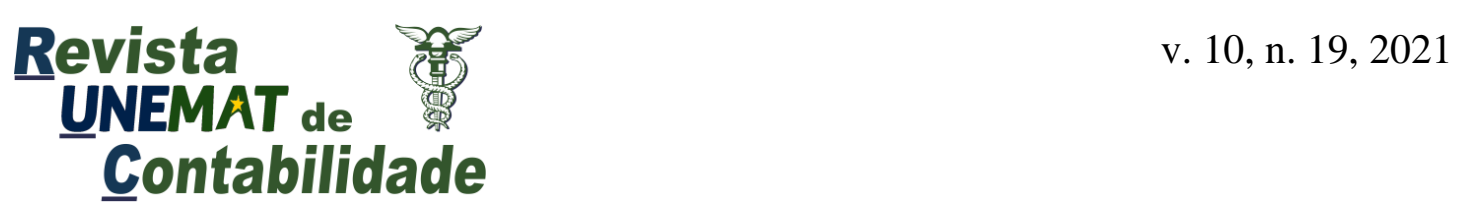

dos cursos de arquitetura, direito, engenharia civil, fisioterapia, jornalismo, nutrição, psicologia e publicidade.

Tabela 1 - Número de alunos por grupo da amostra pesquisada

\begin{tabular}{ccc}
\hline Área & Frequência Absoluta & Frequência Relativa (\%) \\
\hline Cursos de Gestão & 221 & 40,19 \\
Demais áreas & 329 & 59,81 \\
\hline
\end{tabular}

FONTE: Dados da pesquisa.

Na Tabela 2 são demonstradas as características descritivas dos alunos dos cursos de gestão. Nota-se que a amostra contempla representantes de todas as fases dos cursos em estudo. O sexo feminino representa $54,75 \%$ do total dos estudantes de cursos de gestão, ao passo que o percentual masculino é de 45,25\%. Ainda nesta tabela, é trazida a faixa etária dos estudantes dos cursos de gestão, sendo que 39,37\% possuem idade entre 17 a 21 anos, 36,65\% têm entre 22 a 26 anos, 15,84\% alunos possuem entre 27 a 31 anos, 5,88\% têm entre 32 a 36 anos e apenas 2,26\% têm 37 anos ou mais. Este percentual majoritário de adolescentes e jovens de até 26 anos é próximo ao obtido em pesquisas correlatas, tais quais as de Santos, Moura e Almeida (2018) e Silveira et al. (2018).

O estado civil solteiro representa a maioria entre os respondentes $(79,19 \%)$, seguido de casado $(10,41 \%)$ e união estável $(8,60 \%)$. Sugere-se que o estado civil solteiro pode estar atrelado a pouca idade dos respondentes. Em mesmo sentido, tem-se uma possível razão para a baixa presença de dependentes perante os respondentes, uma vez que, cerca de $86 \%$ da amostra declarou não os possuir. O perfil jovem, solteiro e sem dependentes, a princípio, sugere uma despreocupação com os gastos pessoais.

Quanto às suas respectivas moradias, os discentes afirmaram, em maioria (aproximadamente 36\%), morarem com suas famílias, sem qualquer tipo de despesas nesse sentido, já outros 17,19\% da amostra possuem casa própria quitada e 16,29\% possuem despesas com aluguel. Uma vez mais, nota-se a possível despreocupação com despesas de caráter essencial (a exemplo da moradia) pela maior parte dos respondentes.

Foi perguntado, ainda, aos estudantes, se estavam empregados atualmente. 86,43\% afirmam que sim, 13,47\% não trabalham. Verificou-se a renda destes alunos, onde 42,99\% ganham entre um a dois salários mínimos, seguidos de 20,81\% que ganham de dois a três salários mínimos, ficando constatado que apenas 9,50\% não possuem qualquer tipo de renda. Esses indicadores, 
aliados aos anteriores, sugerem que eventuais endividamentos pessoais são decorrentes, de uma forma geral, da falta de planejamento financeiro, dado que parte considerável da amostra aufere algum tipo de renda mensal e, ao mesmo tempo, não possui despesas fixas.

Tabela 2 - Perfil dos estudantes de gestão

\begin{tabular}{|c|c|c|c|}
\hline Variáveis & Categoria & $\begin{array}{l}\text { Frequência } \\
\text { Absoluta }\end{array}$ & Frequência Relativa (\%) \\
\hline \multirow{4}{*}{ Fase } & $1^{\mathrm{a}}$ a $2^{\mathrm{a}}$ Fase & 53 & 23,98 \\
\hline & $3^{a}$ a $4^{a}$ Fase & 31 & 14,03 \\
\hline & $5^{a}$ a $6^{a}$ Fase & 94 & 42,53 \\
\hline & $7^{\mathrm{a}}$ a $8^{\mathrm{a}}$ Fase & 43 & 19,46 \\
\hline \multirow{2}{*}{ Gênero } & Feminino & 121 & 54,75 \\
\hline & Masculino & 100 & 45,25 \\
\hline \multirow{5}{*}{ Faixa Etária } & 17 a 21 anos & 87 & 39,37 \\
\hline & 22 a 26 anos & 81 & 36,65 \\
\hline & 27 a 31 anos & 35 & 15,84 \\
\hline & 32 a 36 anos & 13 & 5,88 \\
\hline & 37 anos ou mais & 5 & 2,26 \\
\hline \multirow{5}{*}{ Estado civil } & Casado & 23 & 10,41 \\
\hline & Outro & 2 & 0,90 \\
\hline & Separado & 2 & 0,90 \\
\hline & Solteiro & 175 & 79,19 \\
\hline & União Estável & 19 & 8,60 \\
\hline \multirow{5}{*}{ Dependentes } & Nenhum & 190 & 85,97 \\
\hline & Um & 18 & 8,14 \\
\hline & Dois & 7 & 3,17 \\
\hline & Três & 1 & 0,45 \\
\hline & 4 ou mais & 5 & 2,26 \\
\hline \multirow{5}{*}{ Moradia } & Casa alugada & 36 & 16,29 \\
\hline & Casa financiada (pagando prestações) & 35 & 15,84 \\
\hline & Casa própria que está quitada & 38 & 17,19 \\
\hline & $\begin{array}{c}\text { Com familiares com auxílio nas } \\
\text { despesas }\end{array}$ & 34 & 15,38 \\
\hline & Com fam. sem desp. com moradia & 78 & 35,29 \\
\hline \multirow{2}{*}{ Trabalha } & Sim & 191 & 86,43 \\
\hline & Não & 30 & 13,57 \\
\hline \multirow{6}{*}{ Renda Mensal } & Até um salário mínimo & 30 & 13,57 \\
\hline & De um a dois salários mínimos & 95 & 42,99 \\
\hline & De dois a três salários mínimos & 46 & 20,81 \\
\hline & De três a cinco salários mínimos & 16 & 7,24 \\
\hline & Mais de cinco salários mínimos & 13 & 5,88 \\
\hline & Não possuo renda & 21 & 9,50 \\
\hline
\end{tabular}

FONTE: Dados da pesquisa. 
O mesmo questionário foi aplicado aos estudantes dos outros cursos, na Tabela 3, onde se pode verificar que cerca de $69 \%$ dos estudantes das demais áreas estão entre a primeira e segunda fase, relevando heterogeneidade dos dados nesse sentido, diferentemente do ocorrido com os discentes de cursos de gestão. Assim como no caso anterior, o gênero feminino é dominante no total de alunos, sendo representado agora por $56,84 \%$ da amostra.

Tabela 3 - Perfil dos estudantes de outras áreas

\begin{tabular}{|c|c|c|c|}
\hline Variáveis & Categoria & $\begin{array}{c}\text { Frequência } \\
\text { Absoluta }\end{array}$ & Frequência Relativa (\%) \\
\hline \multirow{5}{*}{ Fase } & $1^{\mathrm{a}}$ a $2^{\mathrm{a}}$ Fase & 228 & 69,30 \\
\hline & $3^{a}$ a $4^{a}$ Fase & 76 & 23,10 \\
\hline & $5^{a}$ a $6^{a}$ Fase & 10 & 3,04 \\
\hline & $7^{\mathrm{a}}$ a $8^{\mathrm{a}}$ Fase & 10 & 3,04 \\
\hline & $9^{\mathrm{a}}$ a $10^{\mathrm{a}}$ Fase & 5 & 1,52 \\
\hline \multirow{2}{*}{ Gênero } & Feminino & 187 & 56,84 \\
\hline & Masculino & 142 & 43,16 \\
\hline \multirow{5}{*}{ Faixa Etária } & 17 a 21 anos & 152 & 46,20 \\
\hline & 22 a 26 anos & 83 & 25,23 \\
\hline & 27 a 31 anos & 43 & 13,07 \\
\hline & 32 a 36 anos & 30 & 9,12 \\
\hline & 37 anos ou mais & 21 & 6,38 \\
\hline \multirow{5}{*}{ Estado civil } & Casado & 35 & 10,64 \\
\hline & Outro & 7 & 2,13 \\
\hline & Separado & 8 & 2,43 \\
\hline & Solteiro & 252 & 76,60 \\
\hline & União Estável & 27 & 8,21 \\
\hline \multirow{5}{*}{ Dependentes } & Nenhum & 246 & 74,77 \\
\hline & Um & 47 & 14,29 \\
\hline & Dois & 30 & 9,12 \\
\hline & Três & 3 & 0,91 \\
\hline & 4 ou mais & 3 & 0,91 \\
\hline \multirow{5}{*}{ Moradia } & Casa alugada & 70 & 21,28 \\
\hline & Casa financiada (pagando prestações) & 35 & 10,64 \\
\hline & Casa própria que está quitada & 81 & 24,62 \\
\hline & Com familiares com auxílio nas despesas & 50 & 15,20 \\
\hline & Com fam. sem desp. com moradia & 93 & 28,27 \\
\hline \multirow{2}{*}{ Trabalha } & Sim & 233 & 70,82 \\
\hline & Não & 96 & 29,18 \\
\hline \multirow{4}{*}{ Renda Mensal } & Até um salário mínimo & 52 & 15,81 \\
\hline & De um a dois salários mínimos & 106 & 32,22 \\
\hline & De dois a três salários mínimos & 56 & 17,02 \\
\hline & De três a cinco salários mínimos & 28 & 8,51 \\
\hline
\end{tabular}




\begin{tabular}{cccc}
\hline & Mais de cinco salários mínimos & 15 & 4,56 \\
\cline { 3 - 4 } Não possuo renda & 72 & 21,88 \\
\hline
\end{tabular}

FONTE: Dados da pesquisa.

Quanto a idade, os alunos das demais áreas seguem o ocorrido com os alunos dos cursos de gestão, sendo a ampla maioria representada por jovens de 17 a 21 anos (46,20\%) ou entre 22 a 26 $\operatorname{anos}(25,23 \%)$.

Assim como nos cursos de gestão, o maior percentual de estado civil entre os graduandos dos outros cursos é solteiro (76,60\%), além de não possuírem dependentes (74,77\%). Enquanto a questão de moradia se mostrou mais homogênea, ainda que a maior parte $(28,27 \%)$ siga a tendência de moradia com os familiares. Destarte, o perfil socioeconômico dos dois subgrupos amostrais, aparentemente, não influenciaria os resultados observados adiante na pesquisa. Isso se confirma na assertiva sobre o emprego, onde a maioria dos estudantes dos demais cursos também revela trabalhar atualmente (70,82\%). Todavia, cabe destacar que, para este subgrupo, o percentual de respondentes com renda zero foi bem maior $(21,88 \%)$.

\subsection{ESTATÍSTICA DESCRITIVA DA EDUCAÇÃO FINANCEIRA DOS RESPONDENTES}

Após a caracterização dos estudantes buscou-se relacionar questões acerca do endividamento dos respondentes. Quando questionados se já tiveram o nome negativado em algum momento, verifica-se que 27,15\% dos alunos de gestão já tiveram seu nome negativado, já o percentual dos demais cursos é de $35,26 \%$. Os números sugerem que os alunos do curso de gestão apresentam um melhor histórico quanto ao acúmulo de dívidas. Os dados são corroborados pelas respostas dos alunos se esses se consideram ou não endividados (autoavaliação). Dos respondentes, $16,74 \%$ dos estudantes dos cursos de gestão consideram-se endividados, já 28,57\% dos graduandos de outras áreas afirmam estarem endividados.

Além da percepção dos próprios alunos, foi questionado o percentual da renda que está comprometida pelos respondentes. Dos estudantes de cursos de gestão, 27,60\% afirmam ter de $1 \%$ a $30 \%$ da sua renda comprometida, 39,82\% consideram ter de $31 \%$ a $60 \%$, 19,46\% responderam que têm de $61 \%$ a $90 \%$, já 13,12\% dizem ter de $91 \%$ a 100\%. Os alunos das demais áreas responderam com os seguintes percentuais: $34,95 \%$ (1\% a $30 \%$ da renda comprometida); $32,83 \%$ 


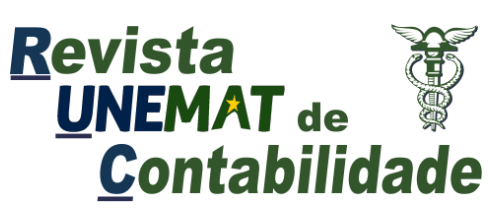

v. 10, n. 19,2021

(31\% a $60 \%$ da renda comprometida); $17,93 \%$ (61\% a $90 \%$ da renda comprometida); e $14,29 \%$ (91\% a $100 \%$ da renda comprometida).

A análise mostra que o percentual de comprometimento da renda, tanto dos estudantes dos cursos de gestão, quanto das demais áreas, é similar, embora tenha ocorrido uma maior disparidade de resultados na primeira (1\% a 30\%) e na segunda faixa (31\% a 60\%). Pode-se considerar, a princípio, que os alunos dos cursos de gestão estão mais endividados do que os alunos dos demais cursos, pois $72,40 \%$ deles estão com a renda comprometida em mais de $30 \%$, contra $65,05 \%$ dos alunos dos demais cursos. Destaca-se ainda que mesmo com um maior percentual de respondentes com mais de $30 \%$ de sua renda comprometida, os alunos de gestão não se consideram endividados, sendo essa percepção possivelmente real, já que estes respondentes apresentaram um menor percentual de indivíduos com o nome negativado.

Sobre reservas de emergência, foi perguntando aos alunos quanto tempo conseguiriam se manter caso tivessem perdido sua renda. Em ambos os cenários há uma aparente dependência de uma única fonte de renda, já que dentre os estudantes de gestão, cerca de 47,5\% afirmam não ter reservas, enquanto isso ocorre para cerca de $50 \%$ dos estudantes dos demais cursos. Junto a isso, foi questionado o percentual de poupança que os respondentes conseguem salvar. Os resultados entre os discentes de cursos de gestão e discentes de outros cursos são próximos, não denotando qualquer tipo de características especiais de cada subgrupo.

Em termos descritivos, foi questionado aos respondentes, por fim, que tipo de investimento possuem, caso possuíssem algum. Foram considerados produtos como poupança, CDB, ações, fundos de investimento, títulos públicos e, ainda, incluída a opção "outros” no questionário. Nessa assertiva os estudantes poderiam marcar mais de uma opção caso possuíssem mais de um investimento. A Tabela 4 apresenta os tipos de investimentos dos estudantes.

Tabela 4 - Investimento dos Estudantes

\begin{tabular}{lcccc}
\hline \multirow{2}{*}{ Investimento } & \multicolumn{2}{c}{ Cursos de Gestão } & \multicolumn{2}{c}{ Demais Cursos } \\
\cline { 2 - 5 } & $\begin{array}{c}\text { Frequência } \\
\text { Absoluta }\end{array}$ & $\begin{array}{c}\text { Frequência } \\
\text { Relativa (\%) }\end{array}$ & $\begin{array}{c}\text { Frequência } \\
\text { Absoluta }\end{array}$ & $\begin{array}{c}\text { Frequência Relativa } \\
(\%)\end{array}$ \\
\hline Ações & 11 & $4,42 \%$ & 5 & $1,46 \%$ \\
CDB & 8 & $3,21 \%$ & 5 & $1,46 \%$ \\
Fundo de Investimento & 11 & $4,42 \%$ & 13 & $3,79 \%$ \\
Outros & 25 & $10,04 \%$ & 25 & $7,29 \%$ \\
Títulos Públicos & 3 & $1,20 \%$ & 3 & $0,87 \%$ \\
Não possuo investimento & 94 & $37,75 \%$ & 148 & $43,15 \%$ \\
Poupança & 97 & $38,96 \%$ & 144 & $41,98 \%$ \\
\hline
\end{tabular}




\begin{tabular}{lllll}
\hline Total & $\mathbf{2 4 9}$ & $\mathbf{1 0 0 \%}$ & $\mathbf{3 4 3}$ & $\mathbf{1 0 0 \%}$ \\
\hline FONTE: Dados da pesquisa. & & & &
\end{tabular}

Dos alunos dos cursos de gestão, 62,25\% afirmam ter algum tipo de investimento entre os citados acima. Já entre os estudantes de outras áreas, 55,02\% declaram possuir investimentos. Apesar de boa parte dos estudantes informarem possuir algum tipo de investimento, se constatou que apenas 23,29\% dos alunos de gestão possuem investimentos além da poupança. Os números são ainda inferiores nos acadêmicos dos demais cursos, no qual apenas 14,87\% possuem outras formas de investimentos. Tal análise corrobora com a afirmação de Cerbasi (2008), quando diz que a poupança é o investimento mais popular no Brasil.

Os dados apresentados pelos estudantes apontam o quanto estes são conservadores quanto aos seus investimentos. Os números ficam ainda mais evidentes ao buscar os estudantes que fazem investimentos em ações, havendo pouca popularidade dessa forma de investimento na amostra estudada (4,42\% para estudantes de gestão e 1,46\% para os demais). Cabe ressaltar que uma parte da amostra observada não possui renda, o que implica em uma não possibilidade de investimentos de qualquer natureza.

\subsection{ANÁLISE FATORIAL E TESTE DE HIPÓTESE}

Dando continuidade aos procedimentos metodológicos elencados previamente, são apresentados na Tabela 5 os resultados da análise fatorial realizada para os 3 constructos acerca do Controle e Orçamento, dispostos no questionário da pesquisa, quais sejam: (I) anoto e controlo gastos pessoais; (II) estabeleço metas financeiras; (III) sigo um orçamento ou plano de gastos. Ressalta-se que este procedimento foi feito visando reduzir a escala de variáveis, unificando as variâncias dos referidos constructos em uma única variável com propriedades métricas para o devido tratamento durante a análise de regressão.

Tabela 5 - Análise fatorial dos constructos

\begin{tabular}{cccccccc}
\hline Constructo & Questão & Fator & H$^{2}$ & MSA & KMO & $\begin{array}{c}\text { Teste de } \\
\text { Bartlett }\end{array}$ & $\begin{array}{c}\text { Alfa de } \\
\text { Cronbach }\end{array}$ \\
\hline Controle e & CF1 & 0,832 & 0,693 & 0,731 & \multirow{2}{*}{0,705} & $\mathrm{X}^{2}=534,957$ & \multirow{2}{*}{ Sig $=0,000$} \\
Orçamento & CF2 & 0,839 & 0,704 & 0,720 & 0,804 \\
& CF3 & 0,873 & 0,762 & 0,671 & & & \\
\hline
\end{tabular}

FONTE: Dados da pesquisa. 


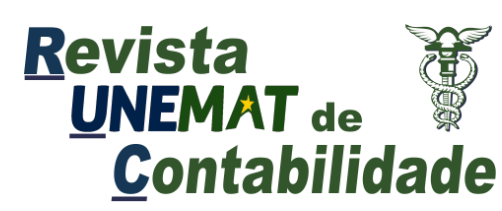

v. 10, n. 19,2021

Legenda: $\mathrm{H}^{2}$ = Comunalidades; MSA = Análise de matriz de anti-imagem; $\mathrm{KMO}$ = teste de adequação da amostra de Kaiser-Meyer-Olklin.

O procedimento foi considerado adequado a partir do aceite dos critérios mínimos estabelecidos por Fávero et al. (2009) para todos os referidos itens. Com isso, a variável CF pôde ser adotada como variável de resposta na Equação 1. Os resíduos da Equação 1, por sua vez, não apresentaram características de normalidade, dado que o p-valor obtido no teste Jarque-Bera foi < 0,000. Todavia, considerando o tamanho da amostra $(n=550)$ e o Teorema do Limite Central, este pressuposto pôde ser relaxado (GUJARATI; PORTER, 2011).

Já no que diz respeito à condição de homocedasticidade, o teste de Breusch-Pagan reportou um p-valor aproximado de 0,004. Sendo assim, a hipótese nula do referido teste não foi aceita, indicando problemas de heterocedasticidade. Foi adotada a correção de White como medida de ajuste para tal resistência. Por fim, os Fatores de Inflação da Variância (FIV) das variáveis independentes foram de: FASE (1,408); IDADE $(1,035)$; CURSO $(1,380)$. Destarte, considerando que os valores são inferiores a 10 unidades, tem-se que não há problemas de multicolinearidade conforme Gujarati e Porter (2011). Dado isso, são apresentados, a seguir, os resultados da Equação 1, na Tabela 7.

Tabela 7. Análise de regressão.

\begin{tabular}{ccccc}
\hline \multicolumn{5}{c}{ Painel A } \\
\hline Coeficiente & Erro Padrão & razão-t & p-valor \\
\hline Intercepto & $-0,0159235$ & 0,177963 & $-0,08948$ & 0,9287 \\
Fase & 0,0197455 & 0,0191195 & 1,033 & 0,3022 \\
Idade & $-0,00678245$ & 0,00721822 & $-0,9396$ & 0,3478 \\
Curso & 0,297434 & 0,0942005 & 3,157 & 0,0017 \\
\hline \multicolumn{5}{c}{ Painel B } \\
\hline $\mathbf{R}^{\mathbf{2}} \mathbf{3}(\mathbf{5 4 6})$ & 0,032249 & $\mathbf{R}^{2}$ ajustado & 0,026932 \\
\hline
\end{tabular}

FONTE: Dados da pesquisa.

Nota-se que o modelo como um todo é estatisticamente significativo, visto que o p-valor (F) é $<0,05$. Ademais, tem-se que o modelo apresenta capacidade preditiva de cerca de $3,2 \%$ $\left(\mathrm{R}^{2}\right)$.

A variável Fase apresenta um p-valor de 0,3022, demonstrando que essa variável não possui influência sobre o nível de educação financeira dos alunos. Essa análise reforça o estudo de Vieira et al. (2014), quando verificaram que o nível de conhecimento de conceitos de finanças entre os alunos das primeiras e últimas fases dos cursos de Administração, Ciências Econômicas e Ciências Contábeis se equiparava. Em relação a variável Idade, o p-valor foi de 0,3478, ou seja, a idade 
BANCO CENTRAL DO BRASIL . Série Cidadania Financeira Estudos sobre Educação, Proteção e Inclusão. Disponível em:

https://www.bcb.gov.br/nor/relincfin/serie_cidadania_financeira_pesquisa_infe_br_\%200443_20 17.pdf. Acesso em 19 jun 2019, 2017.

BRITO, L. S.; BAPTISTA, J; SILVA, S.; BRAZ, S.; HENRIQUE, M. A importância da educação financeira nos contextos acadêmico e profissional: um levantamento de dados com alunos universitários. In: IX Simpósio de Excelência em Gestão e Tecnologia - SEGeT, IX, 2012. Anais... Resende, 2012.

BRYMAN, Alan. Research methods and organization studies. Routledge, 2003.

CERBASI, Gustavo. Investimentos inteligentes. Thomas Nelson Brasil, 2008.

CONFEDERAÇÃO NACIONAL DOS DIRIGENTES LOJISTAS (CNDL); Serviço De Proteção Ao Crédito Do Brasil (SPC Brasil). Cenário da Poupança e dos Investimentos dos Brasileiros. Disponível em:

<http://www.cvm.gov.br/export/sites/cvm/menu/investidor/estudos/pesquisas/20181002_estudo_ spc_cenario_da_poupanca_e_dos_investimentos_dos_brasileiros.pdf. Acesso em 16 jul 2019, 2018.

DONADIO, R. Educação financeira de estudantes universitários: uma análise dos fatores de influência. Tese (Doutorado em administração) - Universidade Nove de Julho. São Paulo, p. 148. 2014.

FÁVERO, L. P. L.; BELFIORE, P. P.; SILVA, F. L. D.; CHAN, B. L. Análise de dados: modelagem multivariada para tomada de decisões. 2009.

FRANKENBERG, L. Seu futuro financeiro: você é o maior responsável. Gulf Professional Publishing, 1999.

GIARETA, M. Planejamento Financeiro Pessoal: Uma proposta de controle de fluxo de caixa para orçamento familiar. Trabalho de Conclusão de Curso de Pós-Graduação (Especialista em Gestão de Negócios Financeiros) - Universidade Federal do Rio Grande do Sul. Porto Alegre, p. 45. 2011.

GUJARATI, D. N.; PORTER, D. C. (2011). Basic econometrics. Boston, Mass: McGraw-Hill, 2011.

HALLES, C. R.; SOKOLOWSKI, R.; HILGEMBERG, E. M. O planejamento financeiro como instrumento de qualidade de vida. I Seminário de Políticas Públicas no Paraná: Escola do Governo e Universidades Estaduais. Curitiba, 2008.

KIYOSAKI, R. T.; LECHTER, S. L. Pai rico pai pobre. Rio de Janeiro: Campus. 2000. 
LEAL, C. P.; NASCIMENTO, J, A. R. Planejamento financeiro pessoal. Revista de Ciências Gerenciais, v. 15, n. 22, 2015.

LEAL, D. T; MELO, S. A contribuição da Educação Financeira para a formação de Investidores. In: Congresso UFSC de Controladoria e Finanças \& Iniciação Científica em Contabilidade, 2., 2008. Florianópolis. Anais... Florianópolis. 2008.

LUCCI, C. R.; ZERRENNER, S. A.; VERRONE, M. A. G.; SANTOS, S. D. A influência da educação financeira nas decisões de consumo e investimento dos indivíduos. In: Seminários em Administração, IX., 2006. São Paulo. Anais... São Paulo, 2006.

MARTINS, G. D. A.; THEÓPHILO, Carlos Renato. Metodologia da investigação cientifica. São Paulo: Atlas, p. 143-164, 2009.

OCDE - Organização para Cooperação e Desenvolvimento Econômico. Improving financial literacy: analysis of issues and policies. Disponível em: https://www.oecd.org/daf/fin/financialeducation/improvingfinancialliteracyanalysisofissuesandpolicies.htm. Acesso em 29 mai 2019, 2005 .

PASTORE, A. C.; PINOTTI, M. C. Inflação e Estabilização: Algumas Lições da I Experiência Brasileira. Revista Brasileira de Economia, v. 53, n. 1, p. 3-40, 1999.

PEREIRA, D. J. Finanças pessoais: estratégias de investimentos. Trabalho de Conclusão de Curso de Pós-Graduação (Especialista em Finanças) - Universidade Federal do Rio Grande do Sul. Porto Alegre, p. 52. 2010.

PIAIA, C. F. Finanças pessoais: estratégias de investimentos. Trabalho de Conclusão de Curso de Graduação (Bacharel em Administração) - Universidade Federal de Santa Catarina. Florianópolis, p. 78. 2008.

REMUND, D. L. Financial literacy explicated: The case for a clearer definition in an increasingly complex economy. Journal of Consumer Affairs, v. 44, n. 2, p. 276-295, 2010.

RICHARDSON, Roberto Jarry et al. Pesquisa social: métodos e técnicas. São Paulo: Atlas, 1999.

ROCHA, S. Pobreza e desigualdade no Brasil: o esgotamento dos efeitos distributivos do Plano Real. Disponível em: http://repositorio.ipea.gov.br/bitstream/11058/2365/1/TD_721.pdf. Acesso em 17 mai 2019, 2000.

RODRIGUES, I. M. S.; CARVALHO, H. A. (2017). Gestão Financeira Pessoal: Uma análise sobre educação financeira com acadêmicos de administração e contabilidade. In: Congresso de Administração Sociedade e Inovação - CASI, X., 2017. Petrópolis. Anais... Petrópolis, 2017. 
SANTOS, E, A.; MOURA, I. V.; ALMEIDA, L. B. Intenção dos Alunos em seguir carreira na área de Contabilidade sob a Perspectiva da Teoria do Comportamento Planejado. Revista de Educação e Pesquisa em Contabilidade (REPeC), v. 12, n. 1, 2018.

SAVOIA, J. R. F.; SAITO, A. T.; SANTANA, F. A. Paradigmas da educação financeira no Brasil. Revista de Administração pública, v. 41, n. 6, p. 1121-1141, 2007.

SILVA, J. G.; SILVA NETO, O. S.; ARAÚJO, R. C. C. Educação financeira de servidores públicos: hábitos de consumo, investimento e percepção de risco. Revista Evidenciação Contábil \& Finanças, v. 5, n. 2, p. 104-120, 2017.

SILVEIRA, T. S.; CASAGRANDE, M. C.; BATISTA, T. C.; MARÇAL, R. R. Ética Profissional: Um estudo sobre a percepção dos alunos de Ciências Contábeis da UFRJ. Revista de Contabilidade e Gestão Contemporânea, v. 1, n. 2, p. 106-125.

SILVESTRE, A. L. Análise de dados e estatística descritiva. Escolar editora. 2007.

SOTTO-MAIOR, F. 2015. Fundos de Investimento: o que são. Disponível em:

https://verios.com.br/blog/fundos-de-investimento-o-que-sao/. Acesso em 23 de jul. 2019.

SPC BRASIL; Confederação Nacional dos Dirigentes Lojistas. 2018. Além dos efeitos da crise, descontrole financeiro está entre principais causas da inadimplência no país. Disponível em: https://www.spcbrasil.org.br/pesquisas/pesquisa/5233. Acesso em 21 de jul. 2019.

STANDARD \& POOR'S. 2019. S\&P Ratings Services Global Financial Literacy Survey. Disponível em: https://gflec.org/wp-content/uploads/2015/11/3313-Finlit_Report_FINAL5.11.16.pdf?x37611. Acesso em 14 de ago. 2019.

TOMMASI, A.; LIMA, F. Viva Melhor Sabendo administrar suas finanças. Editora Saraiva. 2007.

VIEIRA, S. F. A; BATAGLIA, R. T. M; SEREIA, V. J. Educação financeira e decisões de consumo, investimento e poupança: uma análise dos alunos de uma universidade pública do norte do Paraná. Revista de Administração, v. 9, n. 3, p. 61-86, 2011. 